\title{
THE USE OF COGNITIVE LINGUISTICS APPROACH IN ELT: IMPLEMENTING IMAGE SCHEMA THEORY TO TEACH PHRASAL VERBS IN TOEFL PREPARATION CLASS
}

\author{
Miftah Royani ${ }^{1}$, Dwi Puji Lestari ${ }^{2}$ \\ ${ }^{1}$ Muhammadiyah Yogyakarta University, Indonesia \\ ${ }^{1}$ royani.miftah@gmail.com \\ ${ }^{2}$ Direct English Yogyakarta, Indonesia \\ ${ }^{2}$ dwi.pujilestari88@gmail.com
}

\begin{abstract}
Dealing with phrasal verbs (PV) in TOEFL test is one of challengingpartsfor students. They usually learn PV by heart. Nevertheless, their PV mastery has not improved because implementing "blind" memorizing without knowing the concept is harder and will only stay temporarily. Besides, it cannot solve the unfamiliar PV in TOEFL test. Based on the problems, it needs a particular method to make students do not only understand PV meaning easier but also learn it meaningfully. This research is classroom action research. It aims to investigate the students' improvement in PV mastery using cognitive linguistics approach. The research objects are beginner level of adult learners in TOEFL Preparation class. The data were collected from observation, interview and written test. Cognitive linguistics approach employed in this research was image schema introduced by Johnson and Lakoff (1987).In image schema concept, PV which has abstract meaning is construed in a concrete visualization of CONTAINER to understand the meaning more easily, practical and fun. By implementing cognitive linguistics approach in teaching PV, teachers activate students' cognition of PV concept which is basically embodied as it arises from human's mind and body experience. The result shows that there is significant improvement in students' PV mastery.
\end{abstract}

Keywords: cognitive linguistics, image schema, phrasal verbs, TOEFL, adult learners

\section{INTRODUCTION}

Language proficiency can be measured from several aspects of masteries. It can be proven from the macro skills mastery which consists of many micro skills which is summed up into language grammar, pronunciation and also vocabulary (Cornel, 1985) as cited in (Sadri and Talebinejad, 2013, p. 1). In English vocabulary, besides single word, there is also compound word or multiword which consists of more than one word such as phrasal verb (PV). According to Hart (2009, p. 1) PV is a type of multiword verb which consist of a verb and a particle. It is used in English for both spoken and written language. In another word, English phrasal verb (PV) is practiced not only in informal language but also in formal language. Therefore, the use of PV cannot be separated from both daily communication and professional purpose.

In Indonesia where English is as foreign language, the use of PV is still lack. Studies have shown that ESL students' knowledge of and use of PVs often lag behind their overall level of fluency and vocabularies acquisition (Hart, 2009, p. 1). Not every English learner can understand the PV meaning moreover use it in practice. Besides English position as foreign language in which its usage is still limited for certain purpose, this condition is caused by at least three other factors. First, since the use of English is limited, the English learners are not familiar with some types of English vocabulary including PV. Second, the structure of PV is not found in any word structure in Indonesian's mother tongue, Bahasa Indonesia. 
Meanwhile, most learners apply knowledge from their native language to the second (or foreign) language (Xhemaili, 2013, p. 1). When students find a greater scale of difference between two languages it leads to negative language transfer. The similarities and dissimilarities in word meanings and forms affect how quickly a learner can acquire a foreign language (Odlin, 1989, p. 77) as cited in (Xhemaili, 2013, p. 1). The last, it is related to the way students learn PV that they mostly learn PV by heart while it is hard to remember.

Though PV is not as fundamental as grammar in English learning, it takes a big role in English proficiency test for EFL learners such as TOEFL and IELTS test. Those tests are usually used as one of standards to determine whether someone is eligible for higher degree of education, scholarship or even jobs which are not only in abroad but also in Indonesia. In spite of the fact that understanding PV is demanding, the teaching method of PV in Indonesian's English teaching has not been various and optimum yet. Teachers mostly teach PV by asking students to memorize "blindly" PV forms and meaning based on their same verbs. Finally, the students memorize as many as PV they could. When teachers taught so, it has been implied that PVs are unsystematic, arbitrary and random (Sadri and Talebinejad, 2013, p. 1). It is maybe a good way at first, but it cannot always been counted on because there will always be unfamiliar PV in English test. Besides, blind memorizing of PV is obviously harder because there is no certain system or concept in it. As the result, blind memorizing is not practical and also burdens the students because in test situation it is not easy to dig their old and complex memories while at the same time they need to compete with the time too. As a result, when memorizing does not help, students will only guess PV's meaning.

Based on the problems mentioned above, it is seen that there are two basic problems in teaching PV. First, blind memorizing without any understanding of the concept of what they memorize is difficult and only stay temporarily. Second, as a result of blind memorizing, it finally drives to a not optimum memorizing result and this technique also cannot solve the unfamiliar PV. Therefore, this research proposes cognitive linguistics approach to teach PV. It offers an easier and fun yet meaningful learning in understanding PV and make students are able to solve the unfamiliar ones. This research aims to investigate the students' improvement in PV mastery using cognitive linguistics approach especially image schema based approach. In image schema concept, the use linguistic aspects such as lexicon and particles are not arbitrary but it is motivated (Lakoff, 1987), (Hampe and Grady, 2005) and (Evans and Green, 2006). PV which has abstract meaning is construed in a concrete visualization of CONTAINER (conceptualization of a variety of objects of various sizes with the same structural elements (Dodge and Lakoff, 2005, p. 6) as cited in (Hampe and Grady, 2005, p. 62) to understand the meaning more easily, practical and fun. By implementing this approach in teaching PV, teachers activate students' cognition of PV concept which is basically embodied as it arises from human's mind and body experience.

The previous researches about the implementation of cognitive linguistics in ELT have been conducted widely in other countries. However in Indonesia, it has not got much attention. Therefore, the previous researches presented here are all from other countries. The first research, in Hong-Kong, Leung Chung-hong (2004) had conducted cognitive linguistics research in ELT entitled The Particle-based Learning of English Phrasal Verbs: A Conceptual Metaphor and Image Schema Based Approach. In Chung-hong's research, he/she discussed the use of both conceptual metaphor and image schema in learning PV under experimental research 
method. Chung-hong explored up, out, off, on, down particles in PV with figurative meaning. The result shows that the students taught PV using particle based learning performed much better in both the tests result and positive attitude in learning PV.

The second research is Contribution of Cognitive Linguistics to TEFL: Presenting Conceptual Meaning in Phrasal Verbs written by Elham Sadri and Mohammad R. Talebinejad (2013). The research examined the effectiveness of cognitive linguistics approach especially Principled Polysemy theory in teaching up, down, in, out PV particles to Iranian students. The findings show that the positive effects of learning PV using cognitive linguistics approach were proven from both students' better understanding and better attitude to PV. The last research is Learning Phrasal Verbs through Conceptual Metaphor proposed by Sachiko Yasuda (2010). In his/her research, Yasuda compare the effectiveness of traditional instruction and cognitive linguistics approach especially conceptual metaphor to teach idiomatic PV with up, down, into, out, off particles to Japanese students. The result shows that the students taught using conceptual metaphor approach performed significantly better than those who are taught using traditional approach.

Based on those previous studies, it shows that the use of cognitive linguistics approach in ELT has been successfully proven. From the previous researches, there are some differences with this present research. First, it is known that those previous researches employed experimental method. Meanwhile this research is classroom action research. Second, though Chong's research implemented image schema approach, but it was intended to teach PV with figurative meaning. In contrast, this research implemented image schema approach to teach PV with literal meaning. Third, there is difference in PV particles examined because this research examined six particles; in, out, on, off, up, and down.The fourth, two previous researchers, Chung-hong (2004) and Sadri and Talebinejad (2013) employed intermediate level of participants. Meanwhile, this research had beginner level students as its participants. The last, the present research is obviously different in terms of research location because it was conducted in Indonesia. Therefore, the present research is still original and visible.

\section{LITERATURE REVIEW}

The discussion of cognitive linguistics is now widespread. It is actually a quite new field in linguistics which firstly came up in 1970s and has been increasingly active in 1980s (Croft and Cruse, 2004, p. 1). It arose as the answer of the traditional view that language is, what Lakoff (1987, p. xi) called abstract and disembodied. The basic principle of cognitive linguistics is that language is not abstract or arbitrarily produced, but it is conceptualized. Croft and Cruse (2004, p. 1) further explained the three major guidance of cognitive linguistics are; language is not autonomous cognitive faculty, grammar is conceptualization, and knowledge of language emerges from language use. Sharing the same idea, Evans and Green (2006, p. 27) mentioned that there are two basic principles of cognitive linguistics shared by cognitive linguists that are Generalisation Commitment and Cognitive Commitment. From those principles, cognitive linguistics clearly sees that language has relation with human's mind and body experience. Therefore, language cannot be seen separately from how human see or think of something.

The unseparated relation between language and human's mind and body experience is embodied on how human conceptualize what they are going to deliver through language. To explain the conceptualization, cognitive linguistics has one of cognitive structures which is image schema. According to Johnson $(2005$, p. 1) as 
cited in (Hampe and Grady, 2005, p. 15), image schema is important primarily because it helps to explain how our intrinsically embodied mind can at the same time be capable of abstract thought and it plays a crucial role in the emergence of meaning and in our ability to engage in abstract conceptualization and reasoning that is grounded in our bodily engagement with our environment.

Image schema is closely related to the human's mind and body experience such as the concept of verticality, motion, path, scalar, shape and size (Hampe and Grady, 2005). Those concepts are categorized in some types of image schemas. This research focuses only on the type of CONTAINER schema. As its name, CONTAINER schema related to the concept of container. Humans will share certain general understandings of what it means for something to be located within a container, and will understand at least part of this without having to reflect upon it or think about it (Johnson, 2005, p. 8) as cited in (Hampe and Grady, 2005, p. 22). For example, if someone said "The key is in my bag", it can be assured that everyone will understand that the location of the key is in the CONTAINER that is bag. The concept of container-based location can also be applied for other prepositions, or in PV they are called particles, such as out, in, on, off, up and down.

Image schema based approach has widely implemented in English Language Teaching (ELT) especially to teach ESL or EFL students. Nonetheless, this approach is unfortunately still rarely found in Indonesian's ELT. As mentioned above, image schema is closely related with preposition or particles. It can help EFL students to understand whatever language aspects related to English preposition. The employment of image schema is needed because native speakers of a language are subconsciously aware of the conceptual and construal bases of spatial scenes; however, non-native language learners who are accustomed to see the relations and events in physical world through the lens of their mother tongue are clueless about that fundamental knowledge (Sadri and Talebinejad, 2013, p. 2). Image schema is chosen as one of approach to improve students understanding in English preposition because of its practicality yet meaningful learning.

One of language aspects which contains preposition is PV. In PV, prepositions are called particles. PV is a type of multiword verb which consists of a verb and one or two elements (Hart, 2009, p. 1) that are particles. Analysed from its meaning, PV is distinguished into two; literal and figurative meaning. This research focuses on the first one. Dealing with the use of image schema to teach PV, image schema helps to give the concept of why one particle is used in preference to another (Yasuda, 2010, p. 2), and it is not simply arbitrary. For instance, in the sentence "Before entering the room, she put off her shoes", the preference to use particle off to explain the verb put instead of other particlesis not arbitrarily chosen. It is motivated or conceptualized because off has one of conceptual meanings that is RELEASE. In teaching PV using image schema, especially CONTAINER schema, teachers activate students' cognition by visualizing the PV particles in CONTAINER and relate it with the meaning of PV verbs.

\section{METHODS}

This research is classroom action research which is believed by many researchers to be an effective way to know the improvement of teacher's performances in instruction and students' achievement in learning English in classroom. The purpose of this research is to investigate the student's improvement in PV mastery through cognitive linguistics approach. This research involved 11 students of TOEFL Preparation class who are in beginner level. According to 
Mettetal (2001, p. 1), classroom action research is a method of finding out what works best in the classroom so that it can improve students' learning. Through this research, the research's objective is expected to be achieved since it started with teacher's serious concern on students' learning problems and teacher's success in giving instruction to enhance student's achievement.

Classroom action research activities have some steps to be followed. Based on Kemmis and Mc Taggart (as cited in Burns, 2010, p. 33), there are repeated cycles which each consists of planning, action, observation and reflection. The first cycle involves the main steps and the result will be used to determine the following cycles. If the result of the first cycles is not like what the researcher expect to be, the second cycles can be the first cycle's revision. The following figure is action research cycles introduced by Kemmis and Mc Taggart (1988) as cited in (Burns, 2010, p. 33):

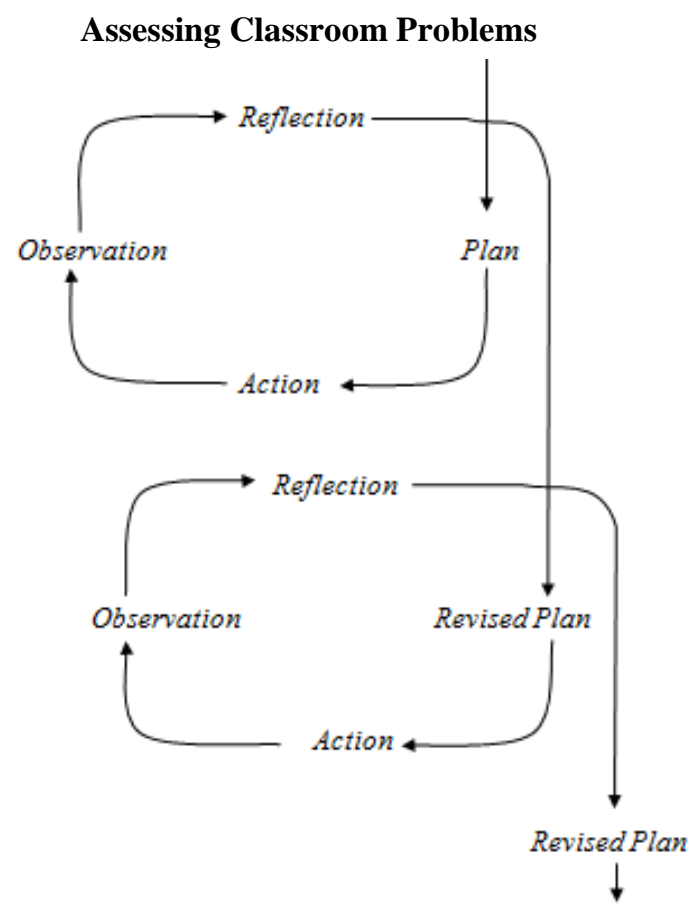

Figure 1: Action Research Cycles

This research has two cycles in which the Cycle 2 comes as a revision of the Cycle 1. After getting to know the students' problem by doing interview and pretest to find out the students' initial understanding, the Cycle 1 began with the plan which prepares all of the things to develop method in teaching PV. In order to achieve the research's objective, certain method was selected to be developed. The method used by the researcher was based on cognitive linguistics approach especially image schema which is believed can effectively improve students' PV mastery. Since the Cycle 1 did not provide much eases in mastering PV, the researchers revised it in the Cycle 2 and it refined the students' mastery. A post-test was administered to be compared with the pretest to show the improvement in each cycle.

Referring to the interview result, the recurrent responses on PV mastery are described in Table 1. 
Table 1: Recurrent Responses on PV Mastery

\begin{tabular}{|c|l|}
\hline No & \multicolumn{1}{|c|}{ Responses } \\
\hline 1 & Understandingphrasal verbs meaning is difficult. \\
\hline 2 & There is no other way to study phrasal verbs instead of memorizing all word and particle. \\
\hline 3 & They have no idea about phrasal verbs. \\
\hline 4 & They cannot use phrasal verbs correctly in sentences. \\
\hline 5 & They feel bored during the phrasal verbs learning process. \\
\hline
\end{tabular}

After conducting the interview, the researcher implemented teaching method based on cognitive linguistics approach. Image schema was applied to explain particles in, out, on, off, up and down. The marks before and after treatments in Cycle 1 were calculated to see whether there were any differences. The marks can

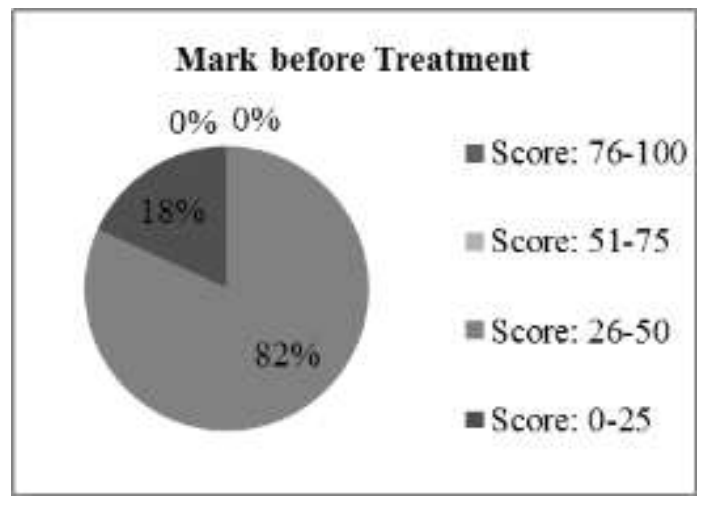

Figure 2: Students' Mark before Treatment

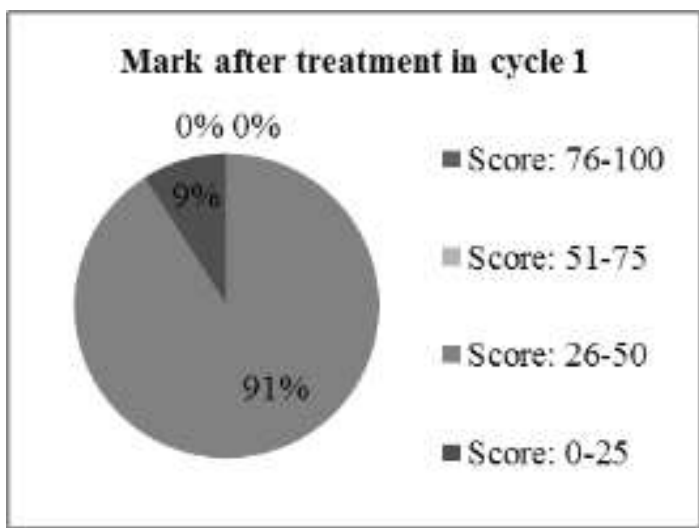

Figure 3: Students' Mark after Treatment Cycle 1

be seen as follows:

While teaching PV strategy using image schema, the researchers observed to evaluate learning activity. In Cycle 1, the researchers conducted some interviews to the students as a reflection during the action. The following table presents the most frequent responses which delivered by the students.

Table 2: Students' Responses in Learning PV using Image Schema in Cycle 1

\begin{tabular}{|c|l|}
\hline No & \multicolumn{1}{c|}{ Responses } \\
\hline 1 & The students find it hard to transfer phrasal verb into visualization. \\
\hline 2 & The students still confuse with some particles. \\
\hline
\end{tabular}

Cycle 2 was conducted by revising the teaching strategy since the mark after treatment in Cycle 1 has no significant refinement and the interviews result reflected that students still have difficulty in understanding PV. The action in Cycle 1 had not facilitated students to apply image schema in sentence context yet so that it did not make much students' engagement in activating cognition. Thus, the revised plan was done to make improvement in Cycle 2. The researchers explained particles in, out, on, off, up, and down by using image schema like what the teacher did in Cycle 1. The difference was the teacher used PV in contextual sentences with its visualizations. The following table presents the most frequent responses which delivered by students in Cycle 2. 
Table 3: Students' Responses in Learning PV using Image Schema in Cycle 2

\begin{tabular}{|c|l|}
\hline No & \multicolumn{1}{c|}{ Responses } \\
\hline 1 & $\begin{array}{l}\text { The students find it interesting learning phrasal verb using image schema visualization of } \\
\text { particles. }\end{array}$ \\
\hline 2 & The students feel surprised about what they experienced in the way they learn phrasal verb. \\
\hline 3 & The students enjoy the activities during the lesson about phrasal verb. \\
\hline 4 & The students are curious about other phrasal verbs. \\
\hline 5 & The students feel excited in analyzingPV in a sentence by exploring their imagination. \\
\hline
\end{tabular}

To validate the result, the researchers observed while conducting teaching learning activities. Some interviews were conducted to the students to know their responses toward the learning activities. Moreover, post-test was also administered in Cycle 2 to know if there is better improvement than in Cycle 1. The researchers conducted written test as a post-test which has similar items with the pre-test. In this written test the students are recommended to use their imagination to visualize $\mathrm{PV}$ in its context. The following figure presents the result of post-test in Cycle 2:

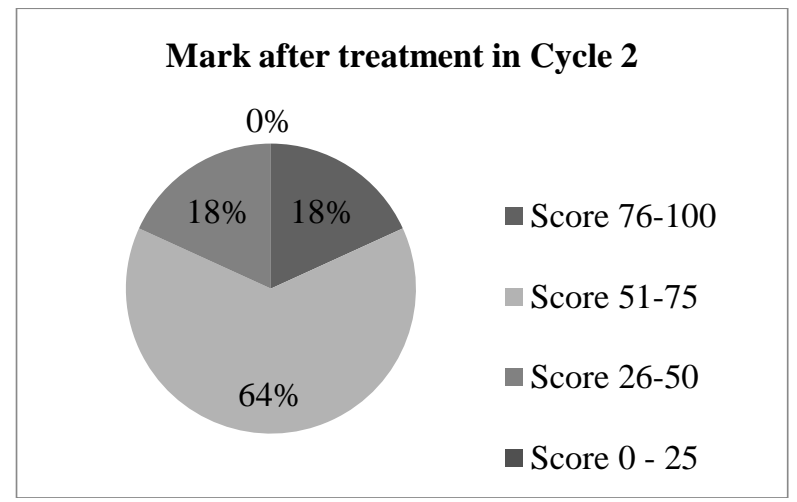

Figure 4: Students' Mark after Treatment in Cycle 2

The figure 4 presents students' mark after having revised treatment in Cycle 2. It shows the results of written evaluation in Cycle 2 in form of 3 score bends appearing in percentage.

\section{FINDINGS AND DISCUSSION}

The findings show that this research has made a significant impact on the students' PV mastery. Figure 4 presents all of the results and shows the difference in every cycle. In pre-treatment students got pretest to know their initial mastery. It can be seen in the chart that $82 \%$ of the students have score bend $26-50$ and $18 \%$ of the students are in the score bend $0-25$ before the action. Then it gets increasing points in Cycle 1. There are $91 \%$ of the students in score bend $26-50$ and $9 \%$ of the students in score bend 0-25. Although it has upward points there are still students whose score in range 0-25. The revised action in Cycle 2 causes upward trends that do not appear in Cycle 1. There are 18\% of the students having score bend 76-100 and $64 \%$ of the students having score bend 51-75. The students with score bend 2650 are $18 \%$ and no students with score bend $0-25$. 


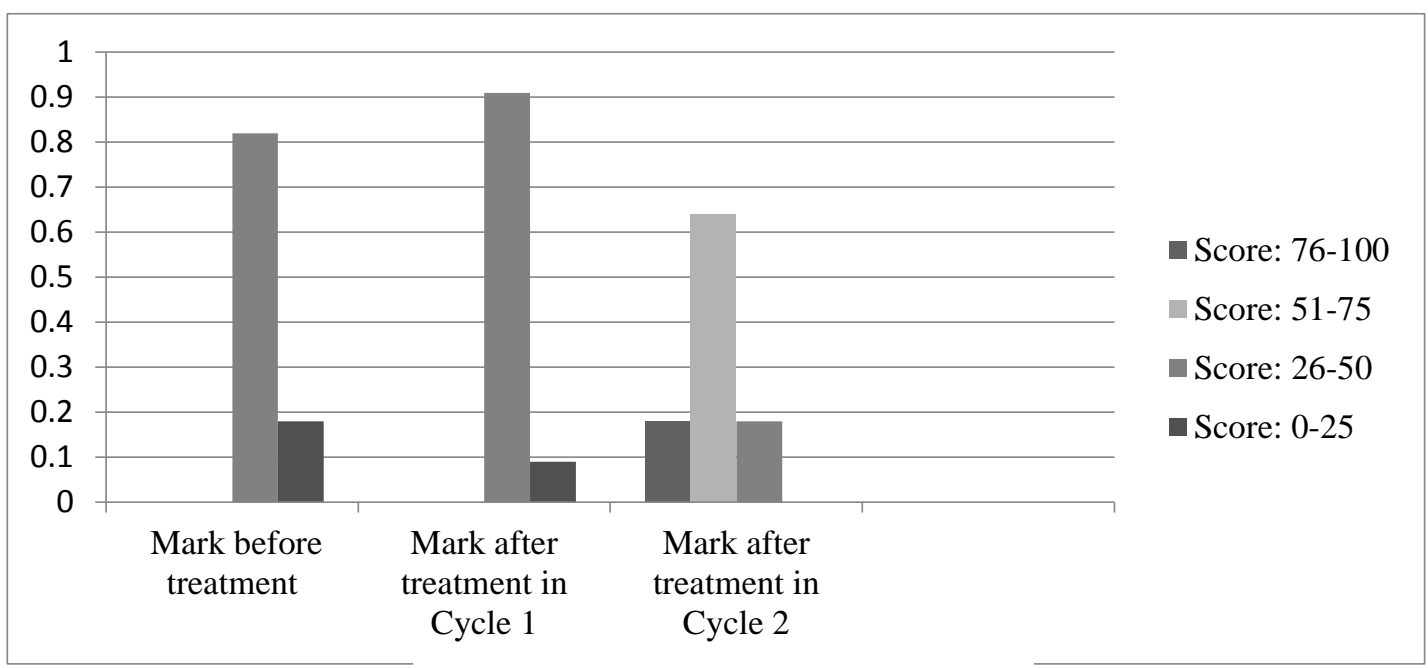

Figure 5: The Comparison of All Data

Although the results showed an improvement, the researcher also conducted interviews during action in Cycle 2. The purpose of the interviews is to observe the students responses toward the action. The interview results are in line with the improvements shown from the evaluation results in the end of the Cycle 2. By having revised action in Cycle 2, the students show their positive responses during the implementation of concrete visualization of image schema. In Cycle 1, students were still hard to understand PV and the researchers found them confused because the action in Cycle 1 had not implemented image schema in sentence context. Therefore, the revised action was made in Cycle 2. Surprisingly, the students were very interested having PV in concrete visualization in Cycle 2. Moreover they impressively experienced what the researchers instructed in class and enjoyed the activities of PV learning. In conclusion, the post evaluation in Cycle 2 and the interview have accomplished refinement.

\section{CONCLUSION}

This research is directed to investigate the students' improvement in PV mastery using cognitive linguistics approach especially image schema based approach. It has two cycles in which each cycle includes planning, action, observation and reflection. Those two cycles provided observation, evaluation and interview as the research instruments to identify whether there is an improvement or not. The teaching method application finally achieved its optimum result after the first revision in Cycle 2. Instead of using "blind" memorizing, PV can be learnt by employing image schema as a concrete visualization as what had been conducted in the present research. Besides giving easier and fun PV learning, employing image schema also provides a meaningful learning. As a result, the method proposed in this research can significantly improve students' mastery in PV.

\section{REFERENCES}

Burns, A. (2010). Doing action research in English language teaching: a guide for practitioners. New York: Routledge.

Chung-hong, Leung. (2004). The particle-based learning of English phrasal verbs: a conceptual metaphor and image schema based approach. $A$ Thesis. The Chinese University of Hong Kong. 
Croft, William \& Cruse, D Alan. (2004). Cognitive linguistics. Cambridge: Cambridge University Press.

Hampe, Beate \& Grady, Joseh E. (2005). From perception to meaning: image schemas in cognitive linguistics. Berlin: Mouton de Gruyter.

Hart, Carl W. (2009). The ultimate phrasal verbs book for ESL and EFL students. $3^{\text {rd }}$ edition. New York: Barron's.

Lakoff, George. (1987). Women, fire, and dangerous things. Chicago: The University Chicago Press.

Mettetal, G. (2001).The what, why and how of classroom action research. The Journal of Scholarship of Teaching and Learning, 2 (1), 1. Retrieved from

https://www.iupui.edu/ josotl/archive/vol_2/no_1/v2n1mettetal.pdf. on August $5^{\text {th }} 2017$ at 09.00 a.m.

Sadri, Elham \& Talebinejad, Mohammad R. (2013). Contribution of cognitive linguistics to TEFL: presenting conceptual meaning in phrasal verbs. World Applied Sciences Journal, 22 (9): 1310-1317. doi: 10.5829/idosi.wasj.2013.22.09.212

Xhemaili, Mirvan. (2013). Literature review on the role of mother tongue in learning and teaching English for specific purpose. Journal of Education and Practice, Vol 4: $39-43$ No. 18. Retrieved from http://www.iiste.org/Journals/index.php/JEP/issue/view/824 on August $12^{\text {th }}, 2017$ at 08.00 p.m.

Yasuda, Sachiko. (2010). Learning phrasal verbs through conceptual metaphors: a case of Japanese EFL learners. TESOL QUARTERLY, Vol. 44: 250-273 No.2. doi:10.5054/tq.2010.219945 